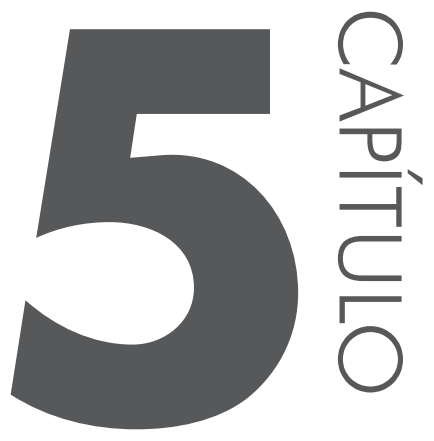

\title{
HÁBITOS ALIMENTARES DE IDOSOS FREQUENTADORES DO CENTRO DE CONVIVÊNCIA DA ZONA LESTE DE LONDRINA
}

Bruna Pimenta de Carvalho Ana Flávia de Oliveira

\section{INTRODUĈ̣̃O}

A alimentação está diretamente presente na vida do homem, exercendo influências marcantes no seu estilo de vida e na sua saúde. Os idosos devem ter mais atenção e cuidado na ingestão de alimentos saudáveis, pois sua saúde, em geral, é um pouco mais debilitada, devido às doenças comuns nessa faixa etária, como a diabetes, a hipertensão arterial e as dislipidemias. 
A cultura alimentar brasileira tem sofrido rápidas transformações paralelas às mudanças no estilo de vida da nossa população. Como oportunidade, a indústria alimentícia tem crescido em seus mercados de comidas congeladas e fast-food. A população idosa merece uma atenção especial nesse cenário, já que sua tradição vem de outra época, em que as refeições eram feitas sempre em casa, preparadas pela própria dona da casa com alimentos comumente mais saudáveis.

Para auxiliar na melhora da qualidade de vida dos idosos da zona leste de Londrina, local onde está inserido o campus da Universidade Tecnológica Federal do Paraná, a universidade criou o projeto de extensão intitulado "Programa de Qualidade de Vida para Idosos", o qual prevê minicursos para os idosos frequentadores do centro de convivência do idoso da região leste de Londrina. Dentre os cursos ofertados, constam aulas de nutrição e saúde. Com o objetivo de conhecer os hábitos da população estudada, este trabalho levantou os hábitos de vida desses idosos, bem como seus hábitos alimentares, a fim de servir de instrumento para novos minicursos e outras estratégias de intervenção nessa população.

\section{IDOSOS NO BRASIL}

O Brasil conta com 14 milhões de pessoas idosas, ou seja, 8,6\% da população total do país, segundo o IBGE (Instituto Brasileiro de Geografia e Estatística), com base no censo 2010. Embora o limite de idade proposto pela OMS (Organização Mundial da Saúde) seja de 60 anos ou mais para os países em desenvolvimento, o IBGE considerou idosas pessoas a partir de 65 anos (IBGE, 2010).

A proporção de idosos vem crescendo mais rapidamente do que a proporção de crianças. Em 1980, existiam cerca de 16 idosos para cada 100 crianças; em 2000, essa relação praticamente dobrou, passando para quase 30 idosos por 100 crianças. Um exemplo é o grupo das pessoas de 75 anos ou mais de idade que teve o maior crescimento relativo $(49,3 \%)$ nos últimos dez anos em relação ao total da população idosa (IBGE, 2002).

No Brasil, as mulheres vivem em média oito anos a mais que os homens. As diferenças de expectativa de vida entre os sexos mostram: em 1991, as mulheres correspondiam a $54 \%$ da população de idosos; em 2000, passaram para 55,1\%. Portanto, em 2000, para cada 100 mulheres idosas havia 81,6 homens idosos. O grau de urbanização da população idosa também acompanha a tendência da população total, ficando em torno de $81 \%$ em 2000 . A proporção de idosos residentes nas áreas rurais caiu de 23,3\%, em 1991, para 18,6\%, em 2000 (IBGE, 2002).

Já em Londrina, PR, a proporção de pessoas com 60 anos ou mais praticamente dobrou de 1980 a 2000. Segundo o censo, em 1980 os idosos eram apenas 
$5,4 \%$ da população Londrinense, índice menor do que a proporção apresentada no mesmo período no Brasil 6,1\%. Em 2000 eram quase 10\% dos londrinenses, 41.700 idosos, ultrapassando a média brasileira que era de $8,5 \%$. Hoje, aproximadamente 43 mil idosos residem em Londrina (LONDRINA, 2010).

\subsection{Alterações fisiológicas nos idosos}

Com o passar do tempo, o organismo apresenta uma série de modificações anatômicas e funcionais, relevantes aos aspectos nutricionais, sendo que uma das maiores alterações é a mudança na composição corporal, cujo tecido adiposo aumenta paralelamente à redução de massa magra, sendo mais acentuada nos rins e no fígado, proporcionalmente intensa também na massa muscular. Essa redução de massa magra, a massa consumidora de oxigênio, reflete diretamente no metabolismo basal (DUTRA-DE-OLIVEIRA; MARCHINI, 1998).

As funções orgânicas decaem como um todo. Por exemplo, a habilidade para responder aos hormônios é reduzida, assim como a capacidade para sintetizar ou degradar proteínas. O colágeno se torna mais fibroso e menos elástico. Já o coração apresenta uma progressiva queda do débito cardíaco e da capacidade aeróbica, o que compromete a sua reserva funcional. Em situações normais, o idoso saudável mantém uma boa função cardíaca, porém, por possuir reserva limitada, reage mal às sobrecargas, podendo assim ser levado à insuficiência cardíaca, que será ainda mais grave caso o paciente tenha o seu estado nutricional comprometido (DUTRA-DE-OLIVEIRA; MARCHINI, 1998).

O sistema renal nessa etapa de vida possui o fluxo plasmático reduzido à metade, sendo que, aos 70 anos, os rins possuem $50 \%$ da sua reserva funcional prévia. Também está reduzida sua capacidade para concentrar ou diluir urina, assim diminui a habilidade para lidar com os produtos do metabolismo a serem eliminados, particularmente água, ureia e sódio, de tal forma que, quando submetido a uma sobrecarga funcional como desidratação ou acidose, o rim do idoso tem uma tem velocidade de depuração muito lenta. Outro fator que influencia negativamente a ingestão de alimentos é a diminuição do olfato, paladar e visão, assim como a coordenação motora fina também fica comprometida e tende a piorar com as doenças neurológicas (DUTRA-DE-OLIVEIRA; MARCHINI, 1998).

\subsection{Doenças frequentes nos idosos}

Algumas doenças que possuem relação direta com a alimentação e nutrição, que são frequentes nos idosos, são a diabetes, a hipertensão e as dislipidemias. 
Fazem parte de um conjunto de doenças que comprometem o sistema cardíaco e são denominadas doenças crônicas não transmissíveis, ou seja, não têm cura, mas possuem tratamento, que inclui, além do uso de medicamentos, alteração do estilo de vida e alimentação (BRASIL, 2006).

A diabetes se enquadra em um grupo de doenças metabólicas caracterizadas por deficiência ou ausência de insulina com consequente hiperglicemia e associadas a complicações, disfunções e insuficiência de vários órgãos, especialmente olhos, rins, nervos, cérebro, coração e vasos sanguíneos. Pode resultar de defeitos de secreção e/ou ação da insulina envolvendo processos patogênicos específicos, por exemplo, destruição das células beta do pâncreas (produtoras de insulina), resistência à ação da insulina, distúrbios da secreção da insulina, entre outros (BRASIL, 2006).

Existem dois tipos de diabetes: a tipo 1 e a tipo 2. A diabetes tipo 1 indica destruição da célula beta que eventualmente leva ao estágio de deficiência absoluta de insulina, quando a administração de insulina é essencial para prevenir cetoacidose, coma e morte. A proposta nutricional, nesse caso, deve levar em consideração a ingestão habitual alimentar somada ao tipo(s) de insulina utilizada, além do exercício físico. Recomenda-se aos pacientes que usam insulina fazer suas refeições diárias em horários definidos, mantendo consistência e sincronia com o tempo de ação de insulina (CUPPARI, 2002).

Já a diabetes do tipo 2, segundo o Ministério da Saúde, é usado para designar uma deficiência relativa de insulina. A administração de insulina nesses casos, quando efetuada, não visa evitar cetoacidose, mas alcançar controle do quadro hiperglicêmico. As dietas hipocalóricas e a perda de peso normalmente melhoram o controle metabólico em longo prazo. Sugere-se uma restrição energética moderada e um plano alimentar equilibrado, com redução de gordura total, sobretudo saturada, controle da ingestão de carboidratos de rápida absorção, acompanhada de exercícios físicos (CUPPARI, 2002).

Outra doença muito frequente nos idosos é a hipertensão arterial, que, segundo o Ministério da Saúde (2004), é uma doença que acomete os vasos sanguíneos, coração, cérebro e olhos, e pode causar paralisação dos rins. Ocorre quando a medida da pressão se mantém frequentemente acima de 140 por $90 \mathrm{mmHg}$. Há vários fatores que influenciam nos níveis de pressão arterial, entre eles: o fumo, o consumo de bebidas alcoólicas, o excesso de peso, o estresse, o consumo excessivo de sal, os níveis altos de colesterol e a falta de atividade física. Além desses fatores de risco, sabe-se que sua incidência é maior na raça negra, aumenta com a idade, é maior entre homens com até cinquenta anos, é maior entre mulheres acima de cinquenta anos e é maior em diabéticos. A hipertensão arterial não tem cura, porém pode ser controlada com auxílio dos medicamentos anti-hiperten- 
sivos e alguns hábitos, como manter peso adequado, diminuir a ingestão de sal, praticar exercício físico, não fumar, evitar consumo de bebidas alcoólicas, evitar alimentos gordurosos e controlar o diabetes.

A dislipidemia se caracteriza por alteração dos níveis séricos normais de lipídeos, que incluem colesterol total alto, HDL-colesterol baixo e altos níveis de LDL-colesterol. Em consequência, a dislipidemia é considerada como um dos principais determinantes da ocorrência de doenças cardiovasculares e cerebrovasculares, dentre elas aterosclerose (espessamento e perda da elasticidade da parede das artérias), infarto agudo do miocárdio, doença isquêmica do coração (diminuição da irrigação sanguínea do coração) e acidente vascular cerebral (AVC). Seu tratamento pode ser de forma medicamentosa ou não medicamentosa, mas de qualquer forma é necessária a inclusão de uma dieta balanceada, com baixo teor de lipídeos, abandono do hábito do fumo, pratica de exercícios físicos e controle do peso (BRASIL, 2011).

\subsection{Alimentação do idoso}

Os idosos têm redução de massa muscular e aumento de tecido adiposo, principalmente na região abdominal, o que favorece, em partes, o aparecimento de doenças cardiovasculares. Assim, esse grupo tem maior risco de desenvolver hipertensão arterial, dislipidemias e diabetes. Dessa forma, os alimentos para essa faixa etária devem ser pobres em açúcares, gorduras saturadas e sódio e, em compensação, precisam ser ricos em fibras (OLIVEIRA; ROMAN, 2013).

A fibra alimentar ou fibra dietética é a parte dos alimentos (vegetais) ingeridos que não é digerida e absorvida pelo organismo para produzir energia. São classificadas em fibra solúvel e insolúvel. São importantes, pois aceleram a passagem dos produtos residuais do organismo, absorvem toxinas e mantém o intestino saudável. Os alimentos ricos em fibras auxiliam na formação de um cólon mais saudável e também podem se unir e inibir a ação de substâncias químicas indesejáveis, reduzindo a possibilidade de se contrair câncer de colón e várias outras doenças gastrointestinais comuns do processo de envelhecimento (SANTOS; VIVIAN, 2011).

Os alimentos para essa faixa etária devem ser saborosos, com temperos naturais, uma vez que há redução das papilas gustativas; devido a isso, muitas vezes o idoso ingere um teor de sal relativamente maior, o que deve ser evitado nessa faixa etária. Para compensar essa questão orienta-se o uso de temperos naturais como salsinha, cebolinha, manjericão, orégano, etc. (OLIVEIRA; ROMAN, 2013). 


\subsection{Pirâmide alimentar}

A pirâmide brasileira de alimentos (Figura 5.1) proposta por Philippi (2008) apresenta os grupos alimentares, e, por conseguinte, mostram quais são os principais nutrientes encontrados em cada grupo alimentar, conforme descrito a seguir:

- grupo do arroz, pão, massa, batata, mandioca: carboidratos;

- grupo das frutas e dos legumes e verduras: ricas em fibras, vitaminas e minerais;

- grupo do leite, queijo e iogurte: são ricos em proteínas e cálcio;

- grupo das carnes e ovos: são ricas em proteínas e ferro (carnes)

- grupo dos feijões e oleaginosas: são ricos em proteínas, fibras e ferro;

- grupo dos óleos e gorduras: são ricas em lipídeos;

- grupo dos açúcares e doces: são ricas em carboidratos (sacarose).

Segundo Oliveira e Roman (2013), a pirâmide alimentar é constituída de quatro andares, os quais representam a quantidade de cada grupo que se deve ingerir ao longo do dia, do que se deve comer em maior quantidade (base) e em menor quantidade (topo). Inicialmente a pirâmide alimentar brasileira utilizava dietas, com diferentes valores energéticos (1.600 kcal, $1.800 \mathrm{kcal} \mathrm{e} 2.200 \mathrm{kcal})$, apresentando números de porções variáveis para cada grupo de alimento. Em 2006, devido à nova legislação de rotulagem alimentar, a pirâmide passou utilizar uma única dieta padrão contendo $2.000 \mathrm{kcal}$, tornando assim as porções exatas para cada grupo de alimento (PHILIPPI, 2008).

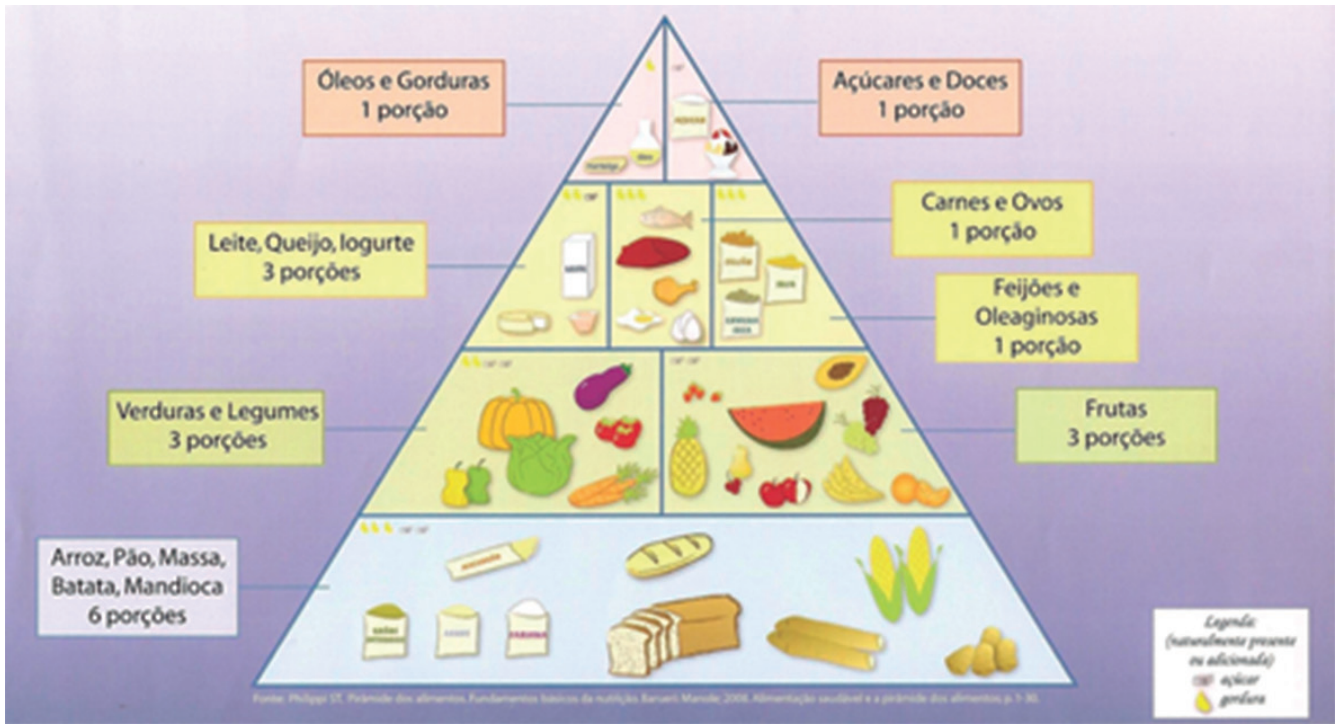

Fonte: Philippi (2008).

Figura 5.1 Pirâmide dos alimentos 
- $1^{\circ}$ nível: grupo do arroz, pão, massa, batata e mandioca. O primeiro nível da pirâmide é formado por alimentos fontes de carboidratos como pão, arroz, macarrão, milho e farinhas. Esses alimentos possuem como principal função fornecer energia para a população.

- $2^{\circ}$ nível: grupo das verduras e legumes e frutas. Esse nível é formado por alimentos com função reguladora que são fonte em vitaminas, minerais e fibras.

- $3^{\circ}$ nível: grupo do leite, queijo, iogurte; grupo das carnes e ovos; grupo dos feijões (leguminosas) e oleaginosas. Esse nível da pirâmide contempla alimentos de 3 grupos diferentes, mas que desempenham a mesma função, construtora. Eles são formados por proteínas, cálcio, fósforo e ferro. O grupo de feijões (leguminosas) inclui todos os tipos de feijões, as lentilhas, ervilhas secas, fava, soja e grão de bico. Já o grupo dos leites e derivados inclui todos os tipos de leite, queijos, coalhadas e iogurtes. As carnes incluem as carnes de vaca, de porco, de aves, peixes e ovos.

- $4^{\circ}$ nível: grupo dos óleos e gorduras e dos açúcares e doces. O grupo dos óleos e das gorduras é formado basicamente por lipídeos. Já o grupo dos açúcares e doces é formado por alimentos compostos predominantemente por açúcares simples (monossacarídeo e dissacarídeo). Recomenda-se o consumo moderado (uma porção) de alimentos desse nível, por possuírem alto valor energético. Estudos recentes apontam que dieta com alta ingestão de alimentos ricos de gorduras e açúcares pode promover um aumento de peso na população e desencadear diversas doenças crônicas.

Segundo Sousa e Guariento (2009), a pirâmide alimentar para os idosos (Figura 5.2) tem como objetivo evitar carências nutricionais e as doenças relacionadas à má alimentação. Algumas recomendações que chamam atenção são:

- ingestão de alimentos rico em fibras, com baixa concentração de gorduras e açúcares refinados e ingestão das quantidades superiores ao número de frações diárias de cada grupo;

- consumir diariamente oito copos de água;

- possível necessidade de suplementação de cálcio e vitamina D para evitar os riscos de fraturas ósseas, além da vitamina B12;

- consumir alimentos integrais, produtos lácteos com pouca gordura, carnes magras, pescados e aves. 


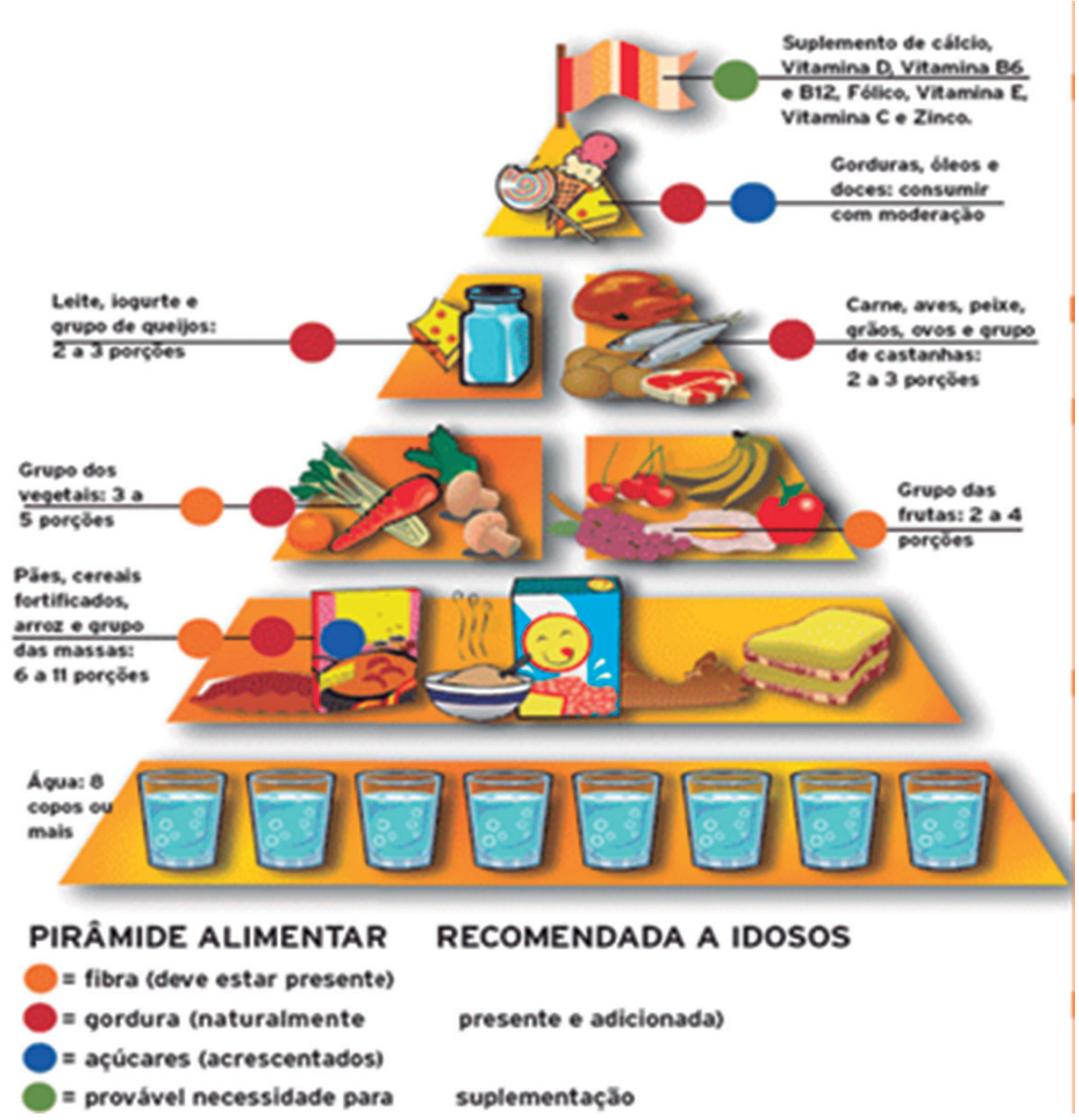

Fonte: Disponível em <http://www.megaartigos.com.br/casamento/relacionamentos/saude-e-gravidez/ dicas-de-alimentacao-na-terceira-idade $\geq$. Acesso em: 30 jan. 2014.

Figura 5.2 Pirâmide alimentar para os idosos

\section{MATERIAIS E MÉTODOS}

O Centro de Convivência da Pessoa Idosa da Zona Leste se situa no Jardim da Luz e é mantido pela prefeitura de Londrina, por meio da Secretaria Municipal do Idoso. O Centro oferece diversas atividades gratuitas, cujo objetivo é proporcionar aos idosos cidadania e conhecimento acerca de seus direitos por meio da socialização de informações, orientações, aprendizado e convivência comunitária. 
Os minicursos sobre alimentação e nutrição enquadram-se no projeto de extensão "Qualidade de vida para idosos", que é uma parceria do centro de convivência com a Universidade Tecnológica Federal do Paraná, campus Londrina.

O presente trabalho trata de uma pesquisa descritiva, e teve como objeto de estudo os hábitos alimentares e de vida dos idosos frequentadores do Centro de Convivência do Idoso da Região Leste de Londrina. Para tal, utilizou-se de um questionário aplicado no último encontro dos minicursos de nutrição ofertados ao longo do segundo semestre de 2013. Houve uma frequência média de trinta idosos ao longo dos cursos ofertados, no entanto, por se tratar de dezembro, apenas onze idosos compareceram ao último encontro, número este que resultou nos dados desta pesquisa.

$\mathrm{O}$ instrumento de coleta de dados foi elaborado pelos autores, abordando os seguintes aspectos: escolaridade, renda mensal, eletrodomésticos na residência, saúde, hábitos alimentares e sugestões para os encontros em 2014. Os questionários foram preenchidos com auxílio de alunos do curso de Tecnologia em Alimentos, de um funcionário do centro de convivência e da orientadora do projeto, uma vez que os idosos tiveram bastante dificuldade em responder sozinhos.

\section{RESULTADOS E DISCUSSÕES}

O centro de convivência possui em torno de cinquenta idosos frequentadores, que recebem aulas de educação física, nutrição, computação, bordado, entre outras atividades ofertadas. Dos onze idosos que responderam ao questionário, dez eram mulheres e apenas um era homem, com idade média de 71,9 anos. Houve poucos participantes, pois a maioria deles já estava de férias. Dos idosos avaliados, dois não estudaram, oito estudaram até o primário e somente um completou o ensino médio, comprovando o baixo grau de instrução/estudo dessa população.

Três são casados ou moram com o companheiro, quatro são viúvos e quatro são separados ou divorciados. A média de filhos entre eles é 4,5 filhos por pessoa, com média de 1,7 pessoas residindo em casa, ou seja, a maioria deles mora sozinho ou com 1 companheiro apenas; no entanto, todos são independentes e realizam todas as suas atividades normalmente.

O Gráfico 5.1 apresenta a faixa de renda, levando em consideração o salário mínimo de 2013, ou seja, R \$ 678,00.

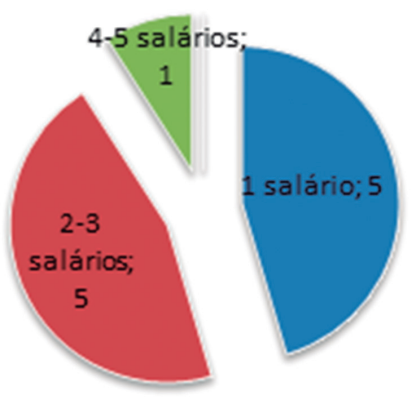

Gráfico 5.1 Média salarial referida pelos participantes 
Dos idosos avaliados, cinco relataram ter entre dois e três salários mínimos, e a mesma quantidade relatou viver de apenas um salário. Embora a maioria more sozinha ou em duas pessoas, sabe-se que este valor pode ser pouco para manter uma alimentação adequada ao longo de um mês.

Todos os idosos que responderam ao questionário possuem água encanada em casa e em apenas duas residências não há rede de esgoto. Esse fato é importante, pois o saneamento básico garante menos infecção e doenças nessa faixa etária, causadas pela queda da imunidade natural da idade.

Todos possuem fogão a gás, geladeira e televisão em casa. Além disso, dois possuem freezer, cinco, micro-ondas, e dois possuem também computador.

Analisando a saúde dos idosos estudados (Gráfico 5.2), apenas dois deles relataram não ter doenças, e os outros possuem até duas delas. O colesterol alto e a hipertensão foram as mais frequentes.

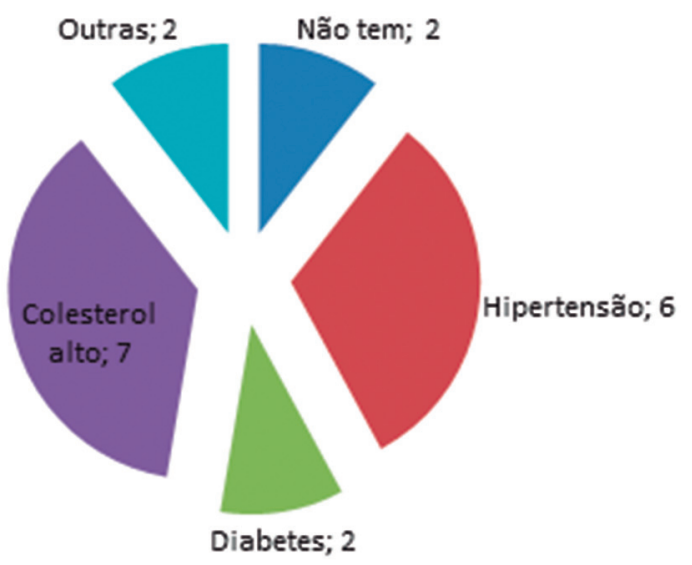

Gráfico 5.2 Doenças referidas pelos participantes

O corpo utiliza de três principais tipos de lipoproteínas para transportar gorduras: as VLDL (Very Density Low Lipoprotein), que transportam triglicerídeos e outros lipídeos fabricados no fígado para as células do organismo para, seu uso; as LDL (Low Density Lipoprotein), que são feitas a partir das VLDL depois que elas doaram grande parte da sua gordura para as células do organismo e captaram colesterol; e as HDL (High Density Lipoprotein), que transportam colesterol das células do organismo para o fígado. Tanto as HDL como as LDL carregam lipídeos no sangue, mas as LDL são maiores, mais leves e mais cheias de lipídeo, enquanto as HDL são menores, mais densas e carregadas com mais proteínas. As LDL distribuem colesterol do fígado aos tecidos e as HDL varrem os excessos de colesterol e fosfolipídeos dos tecidos e retornam ao fígado para destinação (SIZER; WHITNEY, 2003). 
O aumento dos níveis de colesterol em indivíduos com idade superior a 65 anos está associado a um aumento do risco de morte por doença cardiovascular. O estilo de vida, a dieta e a atividade física estão relacionados com a alteração dos valores de colesterol (MARQUES, 2008).

Nove dos entrevistados não são fumantes e nunca fumaram, o que auxilia na boa saúde desses idosos, considerando o malefício que o uso do cigarro causa na saúde de quem possui esse hábito. Apenas dois dos idosos foram fumantes.

Aliado a uma boa alimentação, a atividade física contribui para uma vida mais saudável e para o fortalecimento muscular. O centro de convivência oferece atividades para incentivar essa prática, e apenas um dos entrevistados não realiza atividade física por ser cadeirante. Dos demais entrevistados, todos praticam, sendo que um realiza exercícios físicos uma vez na semana, quatro, duas vezes na semana, e cinco realizam atividades físicas três ou mais vezes na semana, concluindo que a maioria deles pratica algum tipo de exercício, contribuindo assim para a própria saúde.

A compra dos alimentos na casa é feita pelos filhos, netos ou pela própria pessoa ou casal, sendo essa compra realizada semanalmente por dez entrevistados e mensalmente por um. A compra semanal é muito válida, pois pode garantir a compra de hortifrúti, portanto auxilia seu consumo habitual. O consumo de frutas, verduras e legumes diariamente auxilia na melhora e na prevenção das doenças frequentes da idade.

Já o preparo dos alimentos é feito, na maioria dos casos, pela própria pessoa ou pelo(a) companheiro(a); para apenas um deles, o preparo é realizado pela filha, o que representa que a maioria dos entrevistados tem uma vida independente e normal.

As refeições realizadas durante o dia são muito importantes de serem seguidas corretamente, pois cada uma oferece nutrientes necessários para manter a saúde. Observando esse ponto, segue no Gráfico 5.3 as refeições realizadas diariamente pelos idosos estudados.

O café da manhã e o almoço são as refeições que todos os entrevistados realizam todos os dias. Os alimentos do café da manhã repõem e fornecem energia. Além disso, o leite e seus derivados contêm cálcio e proteínas, e as frutas possuem fibras. Dessa forma, se faz importante não pular essa primeira refeição do dia. Já o almoço é uma das refeições em que, geralmente, toda a população realiza, porém, esta deve conter todos os nutrientes necessários, não sendo saudável trocá-la por lanches, salgados etc. Recomenda-se comer a cada três horas, pois o jejum prolongado aumenta o consumo de alimentos inadequados, fora do horário das refeições. 


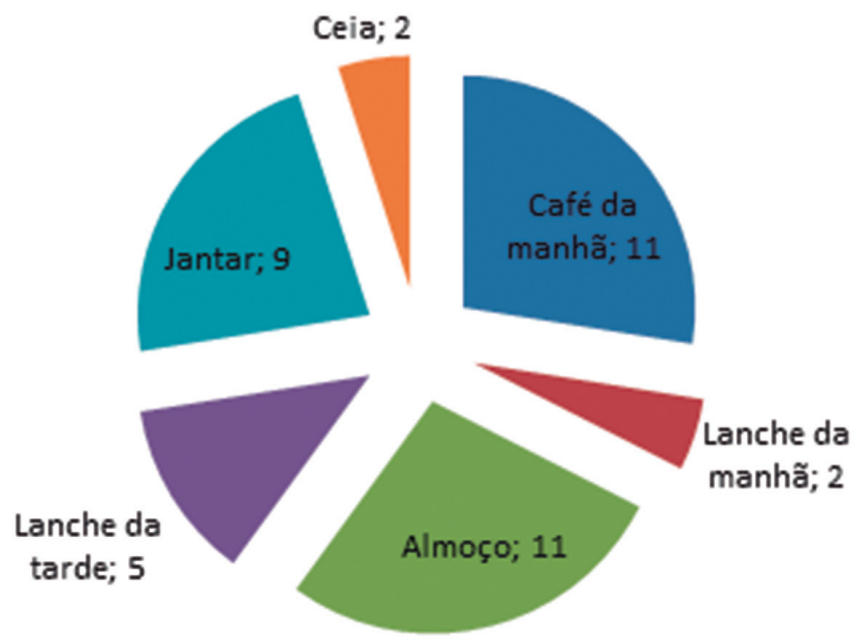

Gráfico 5.3 Refeições diárias realizadas referidas pelos participantes

Por meio da frequência alimentar, foi possível analisar o consumo dos grupos alimentares da pirâmide de alimentos, bem como de alimentos considerados não saudáveis e prejudiciais à saúde, conforme pode ser mais bem observado na Tabela 5.1.

Tabela 5.1 Análise da frequência de consumo de grupos alimentares pelos idosos, Londrina, 2013

\begin{tabular}{|c|c|c|c|c|c|c|c|c|c|c|}
\hline \multirow{2}{*}{ Alimento } & \multicolumn{2}{|c|}{ Diariamente } & \multicolumn{2}{|c|}{$\begin{array}{l}\text { 3-4 vezes por } \\
\text { semana }\end{array}$} & \multicolumn{2}{|c|}{$\begin{array}{l}1-2 \text { vezes } \\
\text { por semana }\end{array}$} & \multicolumn{2}{|c|}{$\begin{array}{l}\text { Consumo } \\
\text { eventual }\end{array}$} & \multicolumn{2}{|c|}{$\begin{array}{c}\text { Não } \\
\text { consome }\end{array}$} \\
\hline & n & $\%$ & n & $\%$ & $n$ & $\%$ & n & $\%$ & $n$ & $\%$ \\
\hline Fruta & 6 & $54,5 \%$ & 3 & $27,3 \%$ & 1 & $9,1 \%$ & 1 & $9,1 \%$ & 0 & \\
\hline Verdura (folha) & 8 & $72,7 \%$ & 2 & $18,2 \%$ & 0 & & 1 & $9,1 \%$ & 0 & \\
\hline Legume & 7 & $63,6 \%$ & 2 & $18,2 \%$ & 1 & $9,1 \%$ & 1 & $9,1 \%$ & 0 & \\
\hline Leite/iogurte/queijo & 7 & $63,6 \%$ & 1 & $9,1 \%$ & 1 & $9,1 \%$ & 2 & $18,2 \%$ & 0 & \\
\hline Carne vermelha & 2 & $18,2 \%$ & 1 & $9,1 \%$ & 3 & $27,3 \%$ & 4 & $36,4 \%$ & 1 & $9,1 \%$ \\
\hline Carne branca & 3 & $27,3 \%$ & 5 & $45,5 \%$ & 2 & $18,2 \%$ & 1 & $9,1 \%$ & 0 & \\
\hline Ovo & 0 & & 1 & $9,1 \%$ & 2 & $18,2 \%$ & 6 & $54,5 \%$ & 2 & $18,2 \%$ \\
\hline Fritura de imersão & 0 & & 0 & & 2 & $18,2 \%$ & 3 & $45,5 \%$ & 5 & $36,4 \%$ \\
\hline $\begin{array}{c}\text { Embutidos (linguiça, } \\
\text { salsicha) }\end{array}$ & 1 & $9,1 \%$ & 1 & $9,1 \%$ & 4 & $36,4 \%$ & 3 & $27,3 \%$ & 2 & $18,2 \%$ \\
\hline Refrigerante & 0 & & 0 & & 3 & $27,3 \%$ & 4 & $36,4 \%$ & 4 & $36,4 \%$ \\
\hline Suco artificial & 0 & & 1 & $9,1 \%$ & 1 & $9,1 \%$ & 2 & $18,2 \%$ & 7 & $63,6 \%$ \\
\hline Temperos prontos & 1 & $9,1 \%$ & 0 & & 1 & $9,1 \%$ & 1 & $9,1 \%$ & 8 & $72,7 \%$ \\
\hline
\end{tabular}


As frutas, verduras, legumes, leites e derivados e carnes são alimentos que devem ser ingeridos diariamente devido ao alto valor nutritivo que oferecem, como micronutrientes, fibras e proteínas. As frutas são ingeridas diariamente somente por um pouco mais da metade dos entrevistados. Pode-se atribuir esse hábito à dificuldade de mastigação, porém a ingestão deste alimento possui fibras que auxiliam no funcionamento intestinal, dão sensação de saciedade e previnem obesidade e colesterol alto.

Já o relato de consumo de verduras foi melhor, porém não devidamente correto. Esse tipo de alimento oferece fibras, vitaminas e minerais e possui baixo valor calórico, ideal para auxiliar na perda de peso. As fibras alimentares têm seu alvo de ação no trato gastrointestinal, e um dos papéis primários é servir de substrato para a microflora normalmente presente no intestino grosso e, além disso, modular a velocidade de digestão e absorção dos nutrientes. Pesquisas mostram que os efeitos da fibra no trato gastrointestinal têm importantes consequências metabólicas que podem resultar em redução do risco de doenças cardiovasculares, de certos tipos de câncer e de diabetes melito, doenças mais comuns em idosos (CUPPARI, 2002).

As pessoas que tomam suplementos de vitaminas $\mathrm{C}$ e $\mathrm{E}$ parecem menos propensas a desenvolver cataratas. Outra vitamina relacionada à saúde dos olhos é a vitamina A. Sua carência pode causar a doença do "olho seco" produzindo secura na pele da córnea. A recomendação de ingestão de vitamina B12 é de 2,4 ug, pois, conforme Sizer e Whitney (2003), pessoas com mais de cinquenta anos reduzem a capacidade de produzir ácido no estômago, consequentemente, reduzem a produção de fator intrínseco, o que diminui a biodisponibilidade da B12.

Os idosos apresentam risco de deficiência de vitamina $\mathrm{D}$ pela baixa ingestão de leite enriquecido com vitamina $\mathrm{D}$, e alguns passam dias sem nenhuma exposição à luz solar, e à medida que as pessoas envelhecem, a síntese de vitamina D declina $75 \%$. A recomendação de ingestão de vitamina D para idosos é de $10 \mathrm{ug}$ diariamente, pois essa vitamina favorece a absorção de cálcio, nutriente importante nessa fase da vida (SIZER; WHITNEY, 2003).

Sabe-se que o leite e seus derivados são extremamente importantes para o idoso, ainda assim nem todos relataram seu consumo diário; além disso, nota-se uma porcentagem considerável para a resposta "eventualmente". A atenção deve ser para a deficiência de cálcio que promove o fortalecimento dos ossos, que já ficam mais frágeis nessa época da vida, e também para a vitamina $\mathrm{D}$, que é produzida pela exposição ao sol, o que ocorre com menos frequência quando comparado às pessoas com menos idade.

A carne vermelha e carne branca apresentam um resultado ainda mais preocupante: seu consumo diário é bem pequeno entre os entrevistados. Esse fato pode se dever também à dificuldade de mastigação, e percebe-se que alguns idosos 
não consomem carne vermelha. Porém, as necessidades de proteínas permanecem aproximadamente as mesmas durante a vida adulta, e, para suprir essa necessidade, devem escolher outros tipos de alimentos que possam suprir essa necessidade, como a ingestão de leguminosas.

Já os alimentos fritos, refrigerantes, suco artificial e temperos prontos devem ser evitados, devido ao alto conteúdo de sódio, conservantes e gordura saturada. Vale ressaltar que o consumo de alimentos ricos em gordura tem relação direta com a obesidade, que, por sua vez, é um fator de risco para o desenvolvimento da artrite, dislipidemias e diabetes, sendo todas essas doenças presentes nesse grupo estudado.

Perguntando sobre o que os idosos utilizam para adoçar seus alimentos, apenas um idoso relatou usar o açúcar light; dois usam o açúcar comum, e oito utilizam o adoçante dietético. $\mathrm{O}$ açúcar normal deve ser evitado, pois eleva os índices de insulina no sangue e possui alto valor calórico. Já o açúcar light é uma mistura entre o açúcar comum e edulcorante dietético, e tem o poder de adoçar duas vezes mais que o tradicional. Ou seja, ao trocar o convencional pelo light, se reduz pela metade a quantidade de açúcar consumido diariamente.

Já o adoçante dietético é uma substância que adoça os alimentos em substituto do açúcar, mas administrado em menores quantidades, já que adoça relativamente mais que a sacarose. Também conhecido como edulcorante, o adoçante pode ser artificial, não contendo calorias, ou natural, contendo menor quantidade de calorias do que o açúcar comum. Dentre os adoçantes artificiais de mesa aprovados e disponibilizados no comércio no Brasil, temos o aspartame, a sacarina, o ciclamato, a estévia, a sucralose e o acessulfame-k.

O pão é um alimento muito consumido nos lares brasileiros. Embora menos consumida, a farinha integral ganhou muito espaço nesse mercado devido ao apelo nutricional, e assim a farinha branca vem sendo substituída cada vez mais, porém o idoso tem uma antiga tradição de fazer o seu próprio pão, e alguns hábitos como esse são muito vistos ainda nos dias atuais. Dos entrevistados, três deles citaram o pão caseiro como o mais consumido; quatro citaram o pão francês; e quatro citaram o pão integral.

Os guias alimentares orientam o consumo de óleos vegetais, sendo o óleo de soja mais vendido e utilizado pelos brasileiros. Nesta pesquisa, um entrevistado relatou utilizar óleo de girassol; um usa óleo de milho; três, o de canola; e seis relataram o uso de óleo de soja. Além disso, quatro deles também citaram o azeite de oliva como óleo utilizado.

O azeite de oliva é rico em ácido oleico, que é um ácido graxo monoinsaturado considerado fundamental pelas propriedades benéficas na redução da oxidação do LDL-colesterol. Portanto, os efeitos benéficos estão especialmente ligados por seu conteúdo de polifenóis e com os seguintes efeitos principais: potente inibi- 
dor de radicais livres, inibidores da oxidação de LDL-colesterol, e inibidores de agregação plaquetária. Os efeitos protetores do azeite de oliva estão correlacionados ao seu conteúdo de ácido graxo monoinsaturado, mas especialmente aos compostos bioativos contidos nele: os polifenóis ativos, funcionais, protegendo a saúde. Dessa forma, a escolha por esse tipo de óleo para o preparo dos alimentos dos idosos, além do sabor diferenciado, ajuda a prevenir os acidentes vasculares cerebrais (ANGELIS, 2001).

Ao perguntar qual assunto sobre nutrição e alimentação eles gostariam de aprender, citaram-se receitas, valor nutricional dos alimentos e reeducação alimentar.

Avaliou-se, como um todo, que os idosos entrevistados neste trabalho não possuem uma alimentação adequada. Esse quadro também foi observado por outros autores. Cardoso (2004), avaliando a alimentação de idosos institucionalizados em Alfenas (MG), observou baixa ingestão de vitaminas do complexo B e cálcio, o que sugere baixa ingestão de carnes e leites e derivados, resultados similares ao encontrado nos idosos aqui avaliados.

Em relação aos alimentos consumidos eventualmente ou não consumidos, outros estudos obtiveram o mesmo resultado deste trabalho. Carvalho, Junior e Sousa (2008) avaliaram os hábitos alimentares de idosos, destacando esses alimentos pouco consumidos: embutidos, leguminosas (exceto o feijão), refrigerantes, produtos de panificação integrais, frituras e refrigerantes.

Schmaltz (2011), ao fazer uma avaliação do consumo alimentar de idosos da cidade de Paracatu, MG, observou uma preocupante insuficiência no consumo de alimentos ricos em cálcio, obtendo resultado semelhante ao avaliar os idosos entrevistados neste trabalho. Nas mulheres, esse fato se torna mais preocupante, pois após os oitenta anos elas absorvem apenas $26 \%$ do mineral consumido, devido às alterações hormonais.

Marques (2008), ao estudar o estado nutricional e a ingestão alimentar numa população de idosos institucionalizados, observou que os cereais integrais e os vegetais são frequentemente evitados pelos idosos pelas dificuldades de mastigação que esses alimentos implicam. O leite é, por vezes, eliminado da dieta desse grupo etário pela frequente intolerância à lactose que esses indivíduos apresentam. Com o objetivo de minimizar o risco do aparecimento da doença cardiovascular, procura-se limitar a inclusão de gorduras (como margarina, manteiga, nata) no esquema alimentar desses indivíduos, uma possível explicação para o baixo consumo de tais alimentos pelos idosos aqui identificados.

\section{CONCLUSÃO}

No presente estudo, concluímos que os idosos entrevistados não possuem uma boa alimentação, o que pode ser atribuído a vários fatores, tais como baixo 
grau de instrução, renda salarial baixa, dificuldade na mastigação ou mesmo falta de orientação. Apesar dos hábitos alimentares inadequados, consideraram-se alguns pontos positivos, como a realização de atividades físicas frequentes e a ausência de fumantes. Diante disso, fazem-se necessários o acompanhamento e o alerta para uma melhoria na alimentação desses idosos.

\section{REFERÊNCIAS}

ANGELIS, R. C. Novos conceitos em nutrição. Reflexões a respeito do elo dieta e saúde. Arq. Gastroenterol., v. 38, n. 4, p. 269-271, 2001.

BRASIL. Biblioteca Virtual em Saúde. Dicas em Saúde. Hipertensão. 2004. Disponível em: $<$ http://bvsms.saude.gov.br/bvs/dicas../52hipertensao.html>. Acesso em: 18 dez. 2013.

. Ministério da Saúde. Secretaria de Atenção à Saúde. Departamento de Atenção

Básica. Diabetes Mellitus. Brasília: Ministério da Saúde, 2006.

. Agência Nacional de Vigilância Sanitária. Saúde e economia. Dislipidemia. 6. ed., out. 2011. Disponível em: <http://portal.anvisa.gov.br/wps/wcm/connect/6011a5 804897a24e8831a8fa35813921/Saude_e_Economia_Dislipidemia_Edicao_n_6_de_ outubro_2011.pdf?MOD=AJPERES>. Acesso em: 13 dez. 2013.

CARDOSO, M. R. V. Alimentação e estado nutricional de idosos residentes em instituições asilares de dois municípios do sul de Minas Gerais. Dissertação (Mestrado em Ciência dos Alimentos) - Universidade Federal de Lavras, Lavras, MG, 2004, 113 p. CARVALHO, G. G.; JUNIOR, J. F. A.; SOUSA, V. M. C. Avaliação dos hábitos alimentares de idosos e formulação de um produto alimentício, 2008. In: XII Encontro Latino Americano de Iniciação Científica e VIII Encontro Latino Americano de Pós-Graduação - Universidade do Vale do Paraíba. Disponível em: <http://www.inicepg.univap.br/cd/ INIC_2008/anais/arquivosINIC/INIC1343_01_O.pdf>. Acesso em: 31 jan. 2014.

CUPPARI, L. Guias de medicina ambulatorial e hospitalar. Nutrição: nutrição clínica no adulto. São Paulo: Manole, 2002.

DUTRA-DE-OLIVEIRA, J. E.; MARCHINI, J. S. Ciências nutricionais. São Paulo: Sarvier, 1998.

IBGE. Instituto Brasileiro de Geografia e Estatística. Censo 2010. Disponível em: <http:// censo2010.ibge.gov.br/resultados>. Acesso em: 30 jan. 2014.

. Instituto Brasileiro de Geografia e Estatística. Perfil dos idosos responsáveis pelos domicílios. 2002. Disponível em: <http://www.ibge.gov.br/home/presidencia/ noticias/25072002pidoso.shtm>. Acesso: 10 nov. 2013.

LONDRINA. Prefeitura Municipal de Londrina. Lei municipal n. 10.741, de 1 de outubro de 2003. Estatuto do idoso. Disponível em: <http://www.londrina.pr.gov.br/dados/images/ stories/Storage/sec_idoso/legislacao/estatuto_idoso.pdf> Acesso em: 5 nov. 2013.

MARQUES, F. S. C. Estado Nutricional e Ingestão Alimentar numa população de idosos institucionalizados. Dissertação (Mestrado em Nutrição Clínica). Faculdade de Medicina, Universidade de Coimbra, Portugal, 2008. $143 \mathrm{f}$. 
NASCIMENTO, C. M. et al. Estado nutricional e condições de saúde da população idosa brasileira: revisão da literatura. Rev Med Minas Gerais, v. 21, n. 2, p. 174-180, 2011.

OLIVEIRA, A. F.; ROMAN, J. A. Nutrição para tecnologia e Engenharia de Alimentos. Curitiba: CRV, 2013.

PHILIPPI, S. T. Pirâmide dos alimentos. Fundamentos básicos da nutrição. Barueri: Manole, 2008.

SANTOS, A. C. O.; MACHADO, M. M. O.; LEITE, E. M. Envelhecimento e alterações do estado nutricional. In: Pernambuco, 2010. Disponível em: <http:/www.sbgg.org.br/ profissionais/arquivo/revista/volume4-numero3/artigo08.pdf>. Acesso em: 13 dez. 2013. SANTOS, F. P.; VIVAN, R. H. F. Atenção ao idoso: ação multiprofissional em saúde. Londrina: EdUnifil, 2011.

SCHMALTZ, R. M. L. C. Avaliação do consumo alimentar de idosos institucionalizados da cidade de Paracatu, MG. Revista Augustus, v.16, n. 32, p. 21-27, 2011.

SIZER, F.; WHITNEY, E. Nutrição. Conceitos e controvérsias. 8. ed. São Paulo: Manole, 2003.

SOUSA, V. M. C.; GUARIENTO, M. E. Avaliação do idoso desnutrido. Rev Bras Clin Med, v. 7, p. 46-49, 2009. 
